\title{
Early Numeracy in Children with Down's Syndrome in Greece
}

\author{
Garyfalia Charitaki'1, Georgios Baralis' ${ }^{1}$, Stavroula Polychronopoulou1, Dionysios Lappas², \\ Georgios Spyridon Soulis ${ }^{3}$ \\ ${ }^{1}$ Faculty of Primary Education, University of Athens, Athens, Greece \\ ${ }^{2}$ Department of Mathematics, University of Athens, Athens, Greece \\ ${ }^{3}$ Faculty of Primary Education, University of Ioannina, Ioannina, Greece \\ Email: Icharitaki@hotmail.com
}

Received 26 June 2014; revised 21 July 2014; accepted 11 August 2014

Copyright (C) 2014 by authors and Scientific Research Publishing Inc.

This work is licensed under the Creative Commons Attribution International License (CC BY).

http://creativecommons.org/licenses/by/4.0/

(c) (i) Open Access

\begin{abstract}
Through this study, we intend to explore the early numeracy of young children with Down's syndrome. Participants were 40 children with Down's syndrome enrolled in special school programs, aged between $7 ; 02(y ; m)$ and $14 ; 07(M=10.07, S D=2.06)$. Survey data was gathered, during the last term of 2013, via questionnaires. As a research tool, it was used the Utrecht Early Competence Test, which is a standardized psychometric test. There is also an attempt to compare the attainments of children with Down's syndrome, with multi-language children, children with special educational needs (enrolled general schools) and typically developing children. The results are discussed in terms of their implications for educational placement.
\end{abstract}

\section{Keywords}

Down Syndrome, Utrecht Early Numeracy Test, Special Educational Needs (SEN), Multi-Language Children, Typically Developing Children

\section{Introduction}

The primary objectives not only for students Down's syndrome, but generally with intellectual disabilities are as follows: successful integration into schools and community settings, successful employment, independent living, successful integration into schools and community settings) and competence in basic life skills (Patton, 1996). Basic arithmetic skills, like counting and solving simple arithmetic problems, is essential for achieving independent living (Brigstocke, Hulme, \& Nye, 2008), and for this reason have been studied by several researchers.

We should note the particular difficulty that students with Down syndrome face in particular cognitive area. 
Besides, we should bear in mind that basic knowledge of counting, which is acquired by the most typical children before formal schooling, they cannot be taken for granted in children with intellectual disabilities of school age (Baroody, 1986). Certainly beyond basic arithmetic skills by several researchers was an attempt to investigate the early mathematical competence which refers to the set of knowledge and skills that are prerequisite to effectively introduce a preschool child or primary school age children in school mathematics of formal education (Van de Rijt, Van Luit, \& Pennings, 1994), since they are components of overall cognitive development of the student.

These knowledge and skills relate mainly to the creation of the concept of number (number sense), as a key area of school mathematics in the early years of formal education is the processing of numerical concepts and relations.

As (Godfrey \& Aubrey, 2001) mentioned, in a recent research, the realistic approach to counting was first formulated as a reaction to the practice of neglecting counting activities in favour of developing structuralist concepts, that is, logical forms of reasoning such as correspondence, seriation and classification. Educators, also, consider very important to identify a number of sub-skills in the counting process, such as verbal control over the number-word sequence, including counting forwards and backwards, resultative counting, which determines amounts and develops separately from control of the number-word sequence and abbreviated or structured counting of ordered and unordered sets of objects, which may be visible or only partly visible. The aim of the study is to investigate all these sub-skills which constitute the components of early numeracy in children with Down's syndrome.

\section{Method}

\subsection{Research Design}

Initially, we contacted with all parents, by epistle, to inform them of the nature of the research and request their assistance. As parents agreed that they allow their children to participate in the research, came into contact with children.

\subsection{Participants}

The participants in this study ( $\mathrm{N}=40$ ), were children with Down's syndrome enrolled in special school programs aged between 7;02 (y;m) and 14;07 $(M=10.07, S D=2.06)$ comprising the entire amount of children with Down syndrome in Attica's special primary education. Their mental age ranged between 4;00 (y;m) and 7;01 $(\mathrm{M}=4.86, \mathrm{SD}=0.96)$.

\subsection{Research Tool for Mathematical Competence}

As a research tool for the Early Mathematical Competence of children with Down's syndrome was used the standardized psychometric Criterion for Early Mathematical Competence of Utrecht (Utrecht Early Mathematical Competence Test), for children $4.00-7.05$. The above research tool is both reliable and valid in terms of content and in terms of its conceptual structure. It comprised eight subtopics, which composed of 5 items, providing 40 items in total. Below we quote the 8 subtopics: concepts of comparison (between two non-equivalent cardinal, ordinal or measure situations), classification (grouping of objects in a class on the basis of one or more features), one-to-one correspondence (counting and pointing to objects at the same time to make a one-to-one relation), seriation (dealing with discrete and ordered entities), using number words (flexibly and in sequence, in this case, 0 to 20, backwards and forwards), structured counting (counting objects in a variety of arrangements), resultative counting (responding to "how many" questions without the need to point and count) and applying general knowledge of numbers in real-life situations.

\section{Results}

The Table 1 presents the descriptive measures of the correct answers in each subscale, in children with syndrome Down. Specifically we can see the average $(M)$, the standard deviation (SD), maximum and minimum value, the skewness and kurtosis of the distribution. As we can easily notice, the students' performance in relational skills (Piagetian subscale) is obviously better, than their performance in counting skills (Gelman subs- 
cale). More specifically, the average of correct answers for relational skills stands at $\mathrm{M}=7.1$ for 20 questions, while the average for counting skills formed at $\mathrm{M}=3.4$ for an equal number of questions. We should also mention that despite the generalized failure on counting skills, there was an outstanding performance in the last topic $(\mathrm{M}=1.50)$. The last topic included applying general knowledge of numbers in real-life situations.

In Table 2 we can see Spearman rho correlation coefficients between prioritized variables. There are mainly moderate and strong positive correlations between subtopics. Noteworthy is also the strong positive correlation between Relational Skills and Counting Skills, for which the Pearson correlation coefficient takes the value $\mathrm{r}=$ 0.774 indicating that children with low scores on the Relational Skills are also expected to have low grades in Counting Skills. Regarding the individual subtopics, the strongest positive correlation is observed between subtopic 1 and 2 with $r=0.740$, which means that children with low scores in activity 1 will also have low score in Activity 2, followed by the correlations between the three activities $3-6 \& 3-10$ with coefficients 0.669 and 0.658 respectively. All these correlations are considered statistically significant at a significance level of a $=1 \%$, while those which are not confirmed statistically at a significance level $\mathrm{a}=5 \%$ are among the activities 1 - 8, 4 7, 4 - 8, 6 - 9 and 7 - 9 which moreover arise as moderate.

Table 1. Descriptive statistics of correct answers in each subtopic.

\begin{tabular}{|c|c|c|c|c|c|}
\hline \multicolumn{6}{|c|}{ Descriptive Statistics of Correct Answers } \\
\hline Subtopics & M & SD & Minimum/Maximum & Skewness & Kurtosis \\
\hline Concepts of comparison & 2.60 & 1.851 & $0 / 5$ & 0.380 & -1.500 \\
\hline Classification & 1.32 & 1.492 & $0 / 5$ & 1.066 & 0.290 \\
\hline One-to-one correspondence & 2.25 & 1.428 & $0 / 5$ & 0.424 & -0.955 \\
\hline Seriation & 0.87 & 1.137 & $0 / 4$ & 1.250 & 0.990 \\
\hline Piagetian subscale (relational skills) & 7.05 & 4.888 & $0 / 18$ & 0.829 & 0.093 \\
\hline Using number words & 0.77 & 1.121 & $0 / 3$ & 1.161 & -0.164 \\
\hline Structured counting & 0.75 & 1.354 & $0 / 5$ & 1.982 & 3.386 \\
\hline Resultative counting & 0.37 & 1.079 & $0 / 5$ & 3.309 & 11.009 \\
\hline $\begin{array}{c}\text { Applying general knowledge of numbers in real-life } \\
\text { situations }\end{array}$ & 1.50 & 1.240 & $0 / 4$ & 0.636 & -0.421 \\
\hline Gelman subscale (counting skills) & 3.40 & 3.960 & $0 / 16$ & 2.000 & 3.777 \\
\hline
\end{tabular}

Table 2. Correlation coefficients (spearman rho) between the subtopics.

\begin{tabular}{|c|c|c|c|c|c|c|c|c|c|c|}
\hline & 1 & 2 & 3 & 4 & 5 & 6 & 7 & 8 & 9 & 10 \\
\hline Concepts of comparison (1) & 1 & $0.740 * *$ & $0.393^{*}$ & $0.582 * *$ & A & $0.378^{*}$ & $0.523^{* *}$ & 0.223 & $0.524^{*}$ & $0.596 * *$ \\
\hline Classification (2) & & 1 & $0.507 * *$ & $0.548 * *$ & A & $0.544^{* *}$ & $0.725^{* *}$ & $0.521^{* *}$ & $0.531^{* *}$ & $0.732 * *$ \\
\hline One-to-one correspondence (3) & & & 1 & $0.369 *$ & A & $0.669 * *$ & $0.535^{* *}$ & $0.401^{*}$ & $0.515^{* *}$ & $0.658 * *$ \\
\hline Seriation (4) & & & & 1 & A & $0.590 * *$ & 0.6002 & 0.249 & $0.331^{*}$ & $0.565^{* *}$ \\
\hline $\begin{array}{l}\text { Piagetian subscale } \\
\text { (relational skills) (5) }\end{array}$ & & & & & 1 & $0.601^{* *}$ & $0.685^{* *}$ & $0.380^{*}$ & $0.600 * *$ & $0.774 * *$ \\
\hline Using number words (6) & & & & & & 1 & $0.773^{* *}$ & $0.515^{* *}$ & 0.260 & A \\
\hline Structured counting (7) & & & & & & & 1 & $0.590 * *$ & 0.289 & A \\
\hline Resultative counting (8) & & & & & & & & 1 & $0.320 *$ & A \\
\hline $\begin{array}{l}\text { Applying general knowledge of } \\
\text { numbers in real-life situations (9) }\end{array}$ & & & & & & & & & 1 & A \\
\hline $\begin{array}{l}\text { Gelman subscale } \\
\text { (counting skills) (10) }\end{array}$ & & & & & & & & & & 1 \\
\hline
\end{tabular}


According to Table 3, it is clear that the development of Relational skills, and Counting skills, with older children showing better performance. Certainly it is clear that longitudinal studies should be conducted. However there are indications that during the age of 4.5 years, students with Down syndrome develop the skill of counting staple quantities, and the ability of classification.

As shown in Table 4, for the effects of gender and age we conducted the hypothesis testing of Student (Independent Samples t-Test). It should be mentioned that for the majority of the activities girls perform a higher average score than boys, for example in Classification rates of 1.41 versus 1.26 and Structured counting $(0.82$ and 0.70 respectively), this was not confirmed statistically since the $p$-value $>a=0.005$. So we can conclude that the effect of gender does not appear to be statistically significant in any activity since $p$-value $>a=0.005$.

The Table 5 identifies the effects of age. The age seems to be statistically significant in relation to the subtopics "One-to-one correspondence" and "Applying general knowledge of numbers in real-life situations", with

Table 3. Descriptive statistics of subscales in relation to the gender of children with Down's syndrome.

\begin{tabular}{|c|c|c|c|c|c|c|c|}
\hline & \multirow{2}{*}{$\begin{array}{c}\text { Sample } \\
\mathrm{n}\end{array}$} & \multicolumn{2}{|c|}{ Mental age } & \multicolumn{2}{|c|}{ Piagetian subscale (relational skills) } & \multicolumn{2}{|c|}{ Gelman subscale (counting skills) } \\
\hline & & M & $\mathrm{SD}$ & M & SD & M & $\mathrm{SD}$ \\
\hline Female & 17 & 4.78 & 1.021 & 7.00 & 5.220 & 3.71 & 3.949 \\
\hline Male & 23 & 4.93 & 0.956 & 7.09 & 4.747 & 3.17 & 4.041 \\
\hline$<4,5$ years & 18 & - & - & 5.67 & 4.589 & 2.83 & 3.863 \\
\hline$>4,5$ years & 22 & - & - & 8.18 & 4.934 & 3.86 & 4.062 \\
\hline All & 40 & 4.86 & 0.974 & 7.05 & 4.888 & 3.40 & 3.960 \\
\hline
\end{tabular}

Table 4. Independent samples student's t-test for the gender effect in each subtopic.

\begin{tabular}{|c|c|c|c|c|c|c|}
\hline Subtopics & Gender & Mean & SD & df & $\mathrm{T}$ & $p$-value \\
\hline \multirow{2}{*}{ Concepts of comparison } & Female & 2.41 & 1.906 & \multirow{2}{*}{38} & \multirow{2}{*}{-0.548} & \multirow{2}{*}{0.587} \\
\hline & Male & 2.74 & 1.839 & & & \\
\hline \multirow{2}{*}{ Classification } & Female & 1.41 & 1.543 & \multirow{2}{*}{38} & \multirow{2}{*}{0.313} & \multirow{2}{*}{0.756} \\
\hline & Male & 1.26 & 1.484 & & & \\
\hline \multirow{2}{*}{ One-to-one correspondence } & Female & 2.29 & 1.404 & \multirow{2}{*}{38} & \multirow{2}{*}{0.166} & \multirow{2}{*}{0.869} \\
\hline & Male & 2.22 & 1.476 & & & \\
\hline \multirow{2}{*}{ Seriation } & Female & 0.88 & 1.219 & \multirow{2}{*}{38} & \multirow{2}{*}{0.035} & \multirow{2}{*}{0.972} \\
\hline & Male & 0.87 & 1.100 & & & \\
\hline \multirow{2}{*}{ Piagetian subscale (relational skills) } & Female & 7.00 & 5.220 & \multirow{2}{*}{38} & \multirow{2}{*}{0.516} & \multirow{2}{*}{0.609} \\
\hline & Male & 7.087 & 4.747 & & & \\
\hline \multirow{2}{*}{ Using number words } & Female & 0.88 & 1.166 & \multirow{2}{*}{38} & \multirow{2}{*}{0.292} & \multirow{2}{*}{0.772} \\
\hline & Male & 0.70 & 1.105 & & & \\
\hline \multirow{2}{*}{ Structured counting } & Female & 0.82 & 1.334 & \multirow{2}{*}{38} & \multirow{2}{*}{-0.110} & \multirow{2}{*}{0.913} \\
\hline & Male & 0.70 & 1.396 & & & \\
\hline \multirow{2}{*}{ Resultative counting } & Female & 0.35 & 0.996 & \multirow{2}{*}{38} & \multirow{2}{*}{0.640} & \multirow{2}{*}{0.526} \\
\hline & Male & 0.39 & 1.158 & & & \\
\hline \multirow{2}{*}{$\begin{array}{c}\text { Applying general knowledge of numbers in } \\
\text { real-life situations }\end{array}$} & Female & 1.65 & 1.272 & \multirow{2}{*}{38} & \multirow{2}{*}{-0.055} & 0.957 \\
\hline & Male & 1.39 & 1.234 & & & 0.008 \\
\hline & Female & 3.705 & 3.949 & & & \\
\hline 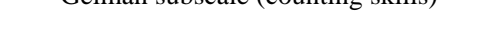 & Male & 3.173 & 4.041 & 50 & 0.410 & 0.000 \\
\hline
\end{tabular}

Note: ${ }^{*}=p<0.05$ 
Table 5. Independent samples student's t-test for the age effect in each subtopic.

\begin{tabular}{|c|c|c|c|c|c|c|}
\hline Subtopics & Age & Mean & SD & df & $\mathrm{t}$ & $p$-value \\
\hline \multirow{2}{*}{ Concepts of comparison } & $<4.5$ & 2.11 & 1.641 & \multirow{2}{*}{38} & \multirow{2}{*}{-1.537} & \multirow{2}{*}{0.133} \\
\hline & $>4.5$ & 3.00 & 1.952 & & & \\
\hline \multirow{2}{*}{ Classification } & $<4.5$ & 1.11 & 1.568 & \multirow{2}{*}{38} & \multirow{2}{*}{-0.817} & \multirow{2}{*}{0.419} \\
\hline & $>4.5$ & 1.50 & 1.439 & & & \\
\hline \multirow{2}{*}{ One-to-one correspondence } & $<4.5$ & 1.61 & 1.290 & \multirow{2}{*}{38} & \multirow{2}{*}{-2.770} & \multirow{2}{*}{$0.009 *$} \\
\hline & $>4.5$ & 2.77 & 1.343 & & & \\
\hline \multirow{2}{*}{ Seriation } & $<4.5$ & 0.83 & 0.857 & \multirow{2}{*}{38} & \multirow{2}{*}{-0.207} & \multirow{2}{*}{0.837} \\
\hline & $>4.5$ & 0.91 & 1.342 & & & \\
\hline \multirow{2}{*}{ Piagetian subscale (relational skills) } & $<4.5$ & 5.66 & 4.588 & \multirow{2}{*}{38} & \multirow{2}{*}{-1.655} & \multirow{2}{*}{0.106} \\
\hline & $>4.5$ & 8.18 & 4.934 & & & \\
\hline \multirow{2}{*}{ Using number words } & $<4.5$ & 0.72 & 1.018 & \multirow{2}{*}{38} & \multirow{2}{*}{-0.266} & \multirow{2}{*}{0.792} \\
\hline & $>4.5$ & 0.82 & 1.220 & & & \\
\hline \multirow{2}{*}{ Structured counting } & $<4.5$ & 0.72 & 1.364 & \multirow{2}{*}{38} & \multirow{2}{*}{-0.116} & \multirow{2}{*}{0.908} \\
\hline & $>4.5$ & 0.77 & 1.378 & & & \\
\hline \multirow{2}{*}{ Resultative counting } & $<4.5$ & 0.33 & 1.029 & \multirow{2}{*}{38} & \multirow{2}{*}{-0.218} & \multirow{2}{*}{0.828} \\
\hline & $>4.5$ & 0.41 & 1.141 & & & \\
\hline \multirow{2}{*}{$\begin{array}{l}\text { Applying general knowledge of numbers in } \\
\text { real-life situations }\end{array}$} & $<4.5$ & 1.06 & 1.056 & \multirow{2}{*}{38} & \multirow{2}{*}{-2.142} & $0030 *$ \\
\hline & $>4.5$ & 1.86 & 1.283 & & & $0.039^{\prime \prime}$ \\
\hline & $<4.5$ & 2.83 & 3.869 & 0 & & 00 \\
\hline Geilmall suUscale (countung skills) & $>4.5$ & 3.86 & 4.062 & 30 & -0.010 & 0.420 \\
\hline
\end{tabular}

Note: ${ }^{*}=p<0.05$

older children achieving better performance.

We should be cautious with the above results because we cannot be absolutely sure about the normality of the distribution of activities, since there were only 5 values.

As we can see in Table 6, the children with Down's syndrome level of performance is quite low. Both Multilanguage children (ML) and children with Special Educational Needs (SEN) seem to achieve better performance in early mathematical competence test, performing an almost equal mean score in Piagetian Subscale (ML:M = 12.58; SD = 5.24 - SEN:M = 12.93; SD = 4.93), while performance in Gelman Subscale shows a clear precedence for Multi-language children (ML:M = 10.07; SD = 6.01 - SEN:M = 7.59; SD = 5.74). A possible explanation may come from the fact that the mean age for children with Down's syndrome who participated in Greece, $\mathrm{M}=58.36$, is quite low.

\section{Discussion}

The results show directly that the level of student performance in Piagetian Subscale was clearly better than the level in Gelman Subscale. In the subtopic of Concepts of comparison, the students could make comparisons with great fluency and almost all responded immediately, which shows that most of the students in the sample have automated the concepts of comparison, since they did not use counting to answer. A possible explanation of this attention has been given by Dehaene (2001) which argued that the ability to manipulate figures shall be innate and is already present in infants. Handling numeric sizes is based on a cognitive system dedicated to the processing of quantitative information, which grows with passing years.

The subtopic of Classification was the second with the lower mean, $\mathrm{M}=1.32$, lever of attainment. One possible interpretation of the above phenomenon may be related to the fact that younger students, undoubtedly try to 
Table 6. Comparative scores for each subtopic.

\begin{tabular}{lccccccc}
\hline & Sample & \multicolumn{2}{c}{ Mental age } & Piagetian subscale (relational skills) & Gelman subscale (counting skills) \\
\hline & $\mathrm{N}$ & $\mathrm{M}$ & $\mathrm{SD}$ & $\mathrm{M}$ & $\mathrm{SD}$ & $\mathrm{M}$ & $\mathrm{SD}$ \\
\hline Current Study & 40 & 58.36 & 11.68 & 7.05 & 4.89 & 3.40 & 3.96 \\
Reference* & 254 & 74.74 & 8.27 & 16.53 & 2.96 & 11.82 & 4.63 \\
Multi-language* & 83 & 76.27 & 13.35 & 12.58 & 12.24 & 10.07 & 6.01 \\
SEN* & 174 & 78.45 & 15.39 & 12.93 & 4.93 & 7.59 & 5.74 \\
Whole* & 511 & 76.25 & 12.07 & 14.67 & 4.25 & 10.09 & 5.59 \\
\hline
\end{tabular}

Note: ${ }^{*}=$ Results of Aunio et al. (2009) study.

organize their experiences in the same way, they wished to impose some type of organization in a series of objects. So, the failure to complete projects such as those included in the subtopic relates to the fact that handling the objects one at a time and the basis of their behavior escapes. They cannot rotate around their own activities and generalize a single fixed criterion that governs the entire sequence. Finally, despite the fact that they can classify objects when only differ in a characteristic, fail when objects have more complex variations (having two or more differences). Finally, according to Inhelder et al. (2013), the skill development of the classification and the generalization is developed as a function of overall cognitive development of the child.

According to the literature, children who understand Seiriation, should deal with various possible answers and will thus reach the right solution. For inference, we should take into account that children who have difficulty in recognizing or constructing lines, work fragmentary (consider only the first and last object) or give almost random responses influenced by a strong perceptual feature of the object. One possible interpretation of the event, may be associated with delayed development of short-term memory (short-term memory) in children with Down, which makes it difficult to retain the information for short periods lasting a few seconds (Bilovsky \& Share, 1964; Broadley \& MacDonald, 1993). The above claim is strengthen by the fact that when students were given the same task in subtasks which first had to put their dogs from largest to smallest, then repeat the same task for the woods and finally assign the larger dog with larger timber, then over the half of the children were able to successfully complete the project in its entirety.

In the subtopic of Using number words, students were asked to count to 20. During the enumeration were observed 3 patterns of errors (Porter, 1999). Students either repeating parts (e.g. 1, 2, 3, 4, 1, 2, 3, 4, 5, 6, 1, 2, 3, 7, $8,9,10,11$ ), or skipped parts (e.g. $1,3,4,5,6,7,8,9,10,12,15$, 20), or using a mixed pattern where repeated errors and omitted parts (e.g. 1, 3, 4, 5, 3, 4, 5, 6, 7, 8, 9, 7, 8, 10, 20). According to Baroody (1999) for learning to count from 0 to 9 they should learn mechanically the sequence of single digits, while counting numbers greater than 10 they should be aware of the changes in decades, discover some type of rule (pattern) and the exceptions to the rule. So, it is very likely that the students of the sample showed the above pattern of errors due to the lack of incentive for discovering patterns in enumeration.

In the subtopic of Structured Counting, students were asked to count sets of objects in a variety of arrangements. It should be noted that the enumeration of a set of objects pre-requires that the child should be able to know the numerical sequence, that each object in a set is assigned a unique number (1 - 1 match) and finally how to keep separate the items that have already been counted and those who have not already been measured, so that each object to measure a single time (Gelman, 1978). Thus, the failure in such tasks may be related to the fact that several students can learn even mechanically the numerical order and have no problem with showing one object at a time, but initially they face a big problem with the coordination of these two skills. We observed that several students during counting, omitted items or counted them more than once, which is a direct result of the lack of effective strategy (keeping-track strategies) (Baroody, 1999). It is clear, that for the acquisition of Resultative Counting skills, children should first, have acquired the skills of Structured Counting. As became clear from the analysis of the results of the sixth topic most students had not reached that level and as expected could not manage the tasks of this subtopic.

In the eighth subtopic, Applying general knowledge of numbers in real-life situations, indicated quite high level of attainments in relation to other subtopics. One possible interpretation of the high level of attainments of students in this subtopic may be associated both with the fact that they were up to matters of everyday life, and 
secondly that the specific activities had the advantage of imaging not only data, but also the possible answers of the requested problem.

Finally, it should be mentioned the fact that there were significant correlations between the 8 subtopics. One interpretation of these findings relates to the theoretical model in which the criterion is built. According to Piaget, the evolution development of the four skills, comparison, classification, matching and seiriothetisis, is at the core of the acquisition of the concept of number. In contrast with Gelman, who claims that children from develop the skill of counting staple quantities very early. The composition of these two contradictory complementary approaches, is used for the interpretation of the development of numerical concepts and relations. At the core of this process there is the development of counting skills, which, however, are governed by the evolution of principles based on the four skills identified by Piaget (Barbas et al., 2008).

\section{Conclusion}

Parents are likely to have a greater impact on their children's development than professionals or other adults because of the substantially greater number of opportunities they have to provide support to their children (Mahoney \& Perales, 2003). Since the basic aim is to encourage parents and teacher to have higher expectations and improvement in functioning for children with Down's syndrome, it is important to inform them about possible cognitive barriers. Providing significant stimuli, but also attempt to motivate children to participate in activities within a game could considerably help the child to gain a deeper conceptual understanding of numbers. Finally both parents and teachers should focus on the systematic errors of children which are the key to overcoming the various cognitive barriers.

\section{References}

Aunio, P., Hautamäki, J., Sajaniemi, N., \& Van Luit, J. E. (2009). Early Numeracy in Low-Performing Young Children. British Educational Research Journal, 35, 25-46. http://dx.doi.org/10.1080/01411920802041822

Barbas, C., Vermeoulen, F., Kioseoglou, G., \& Violet, C. (2008). Psychometric Test Early Mathematical Competence of Utrecht (Adaptation-Weighting). The Project OP "Psychometric-Differential Assessment of Children and Adolescents with Learning Difficulties”, Thessaloniki.

Baroody, A. J. (1986). Counting Ability of Moderately and Mildly Handicapped Children. Education \& Training of the Mentally Retarded, 21, 289-300.

Baroody, A. J., \& Wilkins, J. L. (1999). The Development of Informal Counting, Number, and Arithmetic Skills and Concepts. In Copley, J. V. (Ed.), Mathematics in the Early Years (pp. 48-65), Washington DC: National Association for the Education of Young Children.

Bilovsky, D., \& Share, J. (1964) The ITPA and Down Syndrome: An Exploratory Study. American Journal of Mental Deficiency, 70, 72-82.

Brigstocke, S., Hulme, C., \& Nye, J. (2008). Number and Arithmetic Skills in Children with Down Syndrome.

Broadley, I., \& MacDonald, J. (1993). Teaching Short Term Memory Skills to Children with Down Syndrome. Down Syndrome Research and Practice, 1, 56-62. http://dx.doi.org/10.3104/reports.11

Dehaene, S. (2001). Précis of the Number Sense. Mind \& Language, 16, 16-36. http://dx.doi.org/10.1111/1468-0017.00154

Gelman, R., \& Gallistel, C. R. (1978). The Child's Understanding of Number. Cambridge: Harvard University Press.

Godfrey, R., \& Aubrey, C. (2001). Assessing Early Mathematical Development. Research in Mathematics Education, 3, 5568. http://dx.doi.org/10.1080/14794800008520084

Inhelder, B., Piaget, J., Brbel, I., \& Jean, P. (2013). The Early Growth of Logic in the Child: Classification and Seriation (Vol. 83). London: Routledge.

Mahoney, G., \& Perales, F. (2003). Using Relationship-Focused Intervention to Enhance the Social-Emotional Functioning of Young Children with Autism Spectrum Disorders. Topics in Early Childhood Special Education, 23, 74-86. http://dx.doi.org/10.1177/02711214030230020301

Patton, J. R. (1996). Individuals with Mild Mental Retardation: Postsecondary Outcomes and Implications for Educational Policy. Education and Training in Mental Retardation and Developmental Disabilities, 31, 75-85.

Porter, J. (1999). Learning to Count: A Difficult Task? Down Syndrome Research and Practice, 6, 85-94. http://dx.doi.org/10.3104/reports.99

Van de Rijt, B. A. M., Van Luit, J. E. H., \& Pennings, A. H. (1994). Diagnostiek en behandeling van achterblijvende voorwaardelijke rekenvaardigheden bij kleuters. Nederlands Tijdschrift voor Opvoeding, Vorming en Onderwijs, 10, $13-25$. 
Scientific Research Publishing (SCIRP) is one of the largest Open Access journal publishers. It is currently publishing more than 200 open access, online, peer-reviewed journals covering a wide range of academic disciplines. SCIRP serves the worldwide academic communities and contributes to the progress and application of science with its publication.

Other selected journals from SCIRP are listed as below. Submit your manuscript to us via either submit@scirp.org or Online Submission Portal.
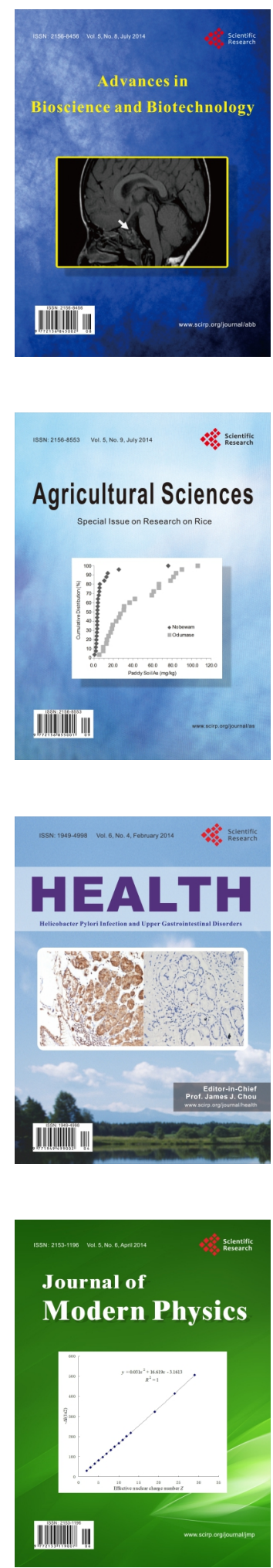
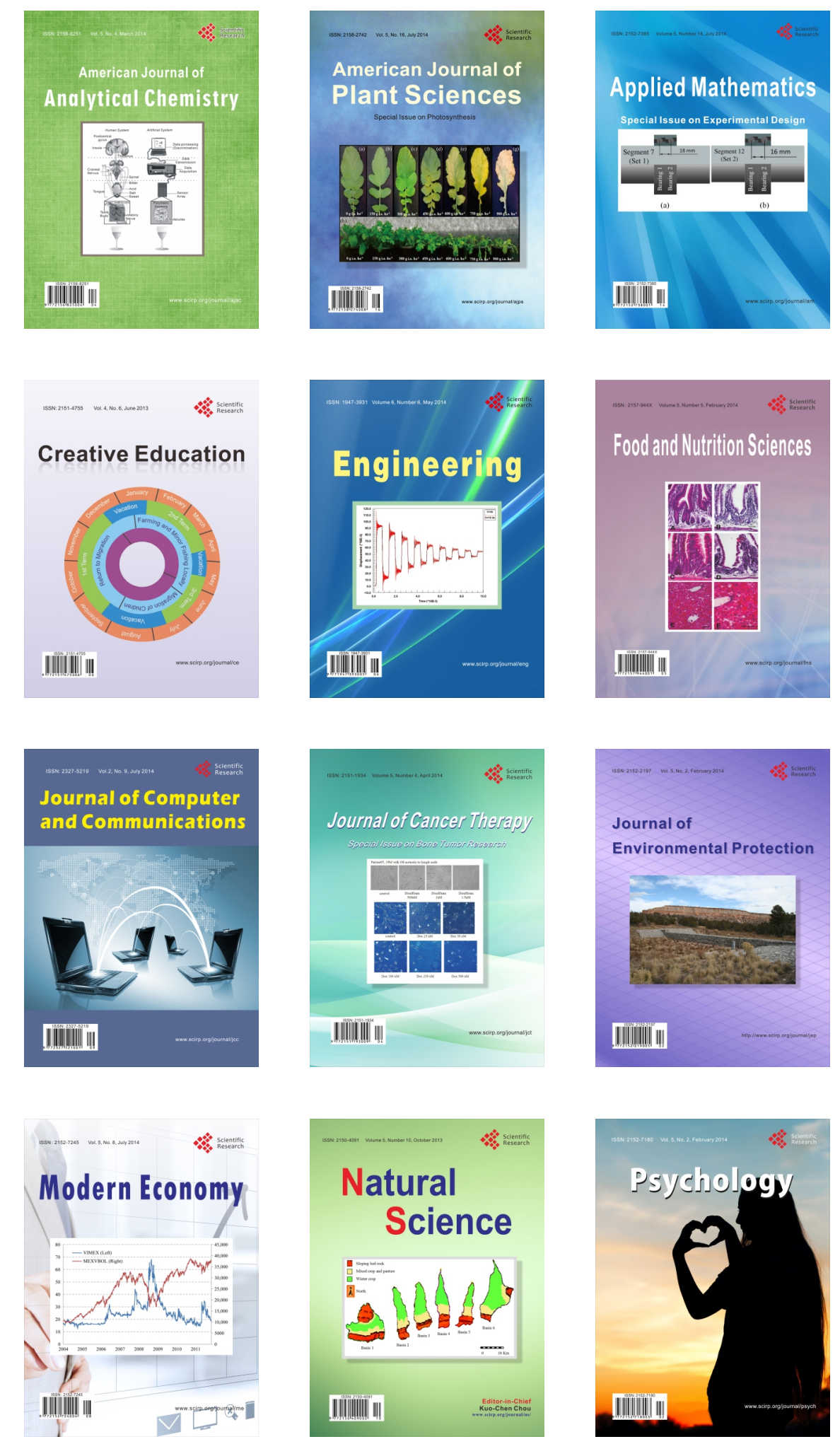